\title{
A preliminary investigation an innovated life-death course for nursing students
}

\author{
Huei-Lih Hwang ${ }^{1}$, Huey-Shyan Lin ${ }^{2}$, Tian-Yuan Kuo ${ }^{*}{ }^{3}$, Hsiu-Hung Wang ${ }^{4}$ \\ ${ }^{1}$ College of Nursing, National Tainan Institution of Nursing, Taiwan \\ ${ }^{2}$ College of Nursing, Fooyin University, Kaohsiung City, Taiwan \\ ${ }^{3}$ College of Humanities and Management, Fooyin University, Kaohsiung City, Taiwan \\ ${ }^{4}$ College of Nursing, Kaohsiung Medical University, Kaohsiung, Taiwan
}

Received: May 21, 2015

DOI: $10.5430 /$ jnep.v6n10p33
Accepted: April 18, 2016

Online Published: May 25, 2016

URL: http://dx.doi.org/10.5430/jnep.v6n10p33

\begin{abstract}
Background: The ever-changing and increasingly complex state of knowledge in higher education requires students to develop high-level critical thinking skills. To deal with complex situations encountered in clinical practice, cultivating the critical thinking skills in classroom is particularly important.

Aims: This study aims to examine the experience of students on an innovative life-and-death studies course. This experience is examined in term of the critical thinking skills, critical thinking disposition, and perceived learning.

Methods: A mixed design of quantitative and qualitative approaches was adopted. The 2-year senior college gerontological care program students were recruited. Critical thinking skills and disposition were assessed and compared in an LDS group ( $\mathrm{n}=36$ ) and a not-LDS group $(\mathrm{n}=34)$ at the beginning and end of semester using a self-report questionnaire. In-depth, focus-group interviews were conducted at end of semester.

Results: No difference between the LDS group and not-LDS group in terms of critical thinking skill $(p=.063)$ and disposition $(p$ $=.89)$, but significant difference in induction skills $(p=.008)$. Focus group interview findings complemented survey findings and revealed themes that reflected the LDS course learning experience of students.

Conclusions: Critical thinking skills can be embedded in LDS course to broader and deeper reflection on death-related issues and further construct knowledge by providing rich experience in the course activities. However, emphasis on systematic design for curriculum and faculty development in teaching critical thinking needs to help create links that students may promote engaged thinking activities within their courses.
\end{abstract}

Key Words: Critical thinking, Life and death studies, Teaching and evaluation

\section{INTRODUCTION}

Critical thinking (CT) is universally considered an important goal of higher education and an essential skill in the $21 \mathrm{st}$ century. ${ }^{[1]}$ Development of CT skills is a core requirement for students ${ }^{[2]}$ and is included in the accreditation guidelines for nursing schools. ${ }^{[3]}$ Paul and Elder ${ }^{[4]}$ claimed that high quality of thought is needed for high quality of life and work; they also argued that CT skills are applicable in both professional and personal life. However, learners do not acquire CT skills naturally. Educators must motivate reflection on these skills and the practical application of these skills. ${ }^{[5,6]}$

Studies have found that domain-specific knowledge facilitates the application of CT by students in various professions including nursing, physical therapy and teaching, ${ }^{[7-9]}$ few

*Correspondence: Tian-Yuan Kuo; Email: sc038@fy.edu.tw; Address: 151 Jinxue Rd., Daliao Dist., Kaohsiung City 83102, Taiwan. 
studies have examined whether CT skills can be taught in life-death studies (LDS) courses, a similar course entitled 'Death and Dying' in western countries. Courses in LDS tend to focus on teaching students to face life and death respectfully rather than on analyzing and evaluating independent thinking skills. ${ }^{[10]}$ However, since life and death issues are inherently ill-defined, students in such courses are encouraged to think without fear of giving the wrong answer, which is one of the most demanding CT skills. Preparing effective nurses is very challenging. To prepare nursing students to deal with the complex life and death issues faced by care receivers, educators cannot rely only on conventional teaching methods. Nursing or gerontology students must be immersed in field work before they can reflect meaningfully and construct practical knowledge. Therefore, educators must guide students in developing CT skills and must understand the importance of high-level CT for responding to life-death issues in a rapidly changing world.

\subsection{Literature review}

Critical thinking is the art of analyzing and evaluating thinking for the purpose of improving thinking. Elder and Paul ${ }^{[4]}$ contended that the scope of CT includes cognitive skills and intellectual dispositions such as intellectual integrity, empathy, humility, courage, perseverance, autonomy, fairmindedness and confidence in reason. Critical thinking dispositions and skills complement each other. To develop a CT disposition, students must first develop a set of CT skills. ${ }^{[4]}$ Critical thinking dispositions and skills can also be taught simultaneously. ${ }^{[1]}$

Classroom instruction in critical thinking skills is particularly important for cultivating and enhancing the skills needed to deal with complex situations encountered in clinical practice. However, students in health-related fields may not be adequately prepared for their future roles in healthcare settings if their education and training are limited to the conventional classroom lecture format. Thus, various classroom learning strategies for facilitating CT in college students have been developed, including problem-based learning, ${ }^{[12]}$ video disc self-learning, ${ }^{[9]}$ reflective journaling, ${ }^{[13]}$ case study with discussion, ${ }^{[14]}$ and asynchronous on-line discussion. ${ }^{[15]}$

Reflective journaling is among the most effective of these strategies because it provides a medium for deeper learning, which enables students to recapture experiences and emancipates them by cultivating the deconstruction and reconstruction skills needed to inquire about their practices and to consider future alternatives. ${ }^{[16,17]}$ To be effective, a reflection strategy must facilitate learners in viewing crucial incidents from varying perspectives. ${ }^{[18]}$ For naïve learners, coupling reflective journaling with field experience can foster deep thinking, ${ }^{[19]}$ help students to connect classroom theory with practice, and help students to acquire the practical knowledge needed to combine noticing, analyzing and taking action. ${ }^{[20]}$ To trigger and promote reflection, educators must enrich the experience of learners through interaction with each other or through interaction between the learner and instructor. ${ }^{[21]}$ Therefore, this study evaluated the use of field experience, case study, dialogue, and discussion for aiding learners in developing skills in reflective journaling.

Intensive effort and practice under structured guidance are required for effective use of reflective journaling in educational settings. ${ }^{[22,23]}$ The Taxonomy of Behavioral Domain Objectives $^{[24]}$ indicates that most items on the Critical Thinking Disposition Scale (CTDS) are higher-order attitudes or behaviors that can only be developed by long-term effort. Regular practice of CT skills is needed to develop the required intellectual traits. ${ }^{[25]}$ Without regular practice, CT dispositions may not improve. Researchers have also reported that the disposition levels of nursing students are positively associated with age, participation in social and scientific activities, and professional experience. ${ }^{[26]}$

For structured guidance, scholars ${ }^{[27]}$ proposed guidelines for iterative and vertical dimensions of reflective journaling , and $\mathrm{Gibb}^{[28]}$ developed a Reflective Model. For both teaching and evaluation purposes, the model developed by Gibb ${ }^{[28]}$ included six components: describing the event in detail, exploring personal feelings, evaluating good and bad aspects of the experience, breaking down the event into parts, determining what else could have done, and planning what to do if the event occurred again. The methods developed in these studies help learners to analyze their responses and practices in a given situation. ${ }^{[29]}$ In this study, students enrolled in an LDS course performed various immersive activities. The students were then facilitated in reflecting on these experience to help them develop CT skills.

\subsection{Conceptual framework}

The design of this course was based on the constructivist learning theory that learning is more efficient in learners who are active knowledge constructors than in those who are passive knowledge receivers. ${ }^{[30]}$ According to constructivist learning theory, knowledge is constructed by personal experience and by the social context of the experience. Learners can construct knowledge by individual reflection or by an interactive process.

\subsection{Research questions}

The research questions that guided the experiment were: (1) does such a LDS course engage students in active reflection? (2) what are the learner perceptions of the course? 


\section{MethodS}

\subsection{Research design}

A mixed design of research methods was used to explore and to examine the experience of students on an innovative life-and-death studies course. The sequential explanatory design of this study ${ }^{[31]}$ included the initial use of a quantitative method followed by the use of a qualitative method to clarify the quantitative results. The comparison study recruited two groups taking the LDS course or not, respectively, and the same questionnaires were administered to the two groups in a pre-test and in a post-test. To aid interpretation of the survey results, focus group interviews were also performed to improve understanding of student perspectives. The independent variable was the LDS course. The dependent variables were the critical thinking performance and perceptions of the course activities participated students enrolled in the LDS course.

In the following discussion, the term reflection is used interchangeably with the term reflective journaling.

\subsection{The LDS course}

The course was delivered in one semester in a class that met

2 hours per week. The coursework was designed to elicit learner' engagement by introducing scenarios and encouraging students to perceive stimuli and respond actively. The students were then asked to link the scenarios to situations they might encounter in their future work and life. The class combined didactic teaching methods with active learning strategies (including reflective journaling, case study, and online discussion). Critical thinking skills were introduced in the first two class sessions. The following six class sessions then focused on life- and death-related knowledge, including psychological, religious, philosophical, sociological and medical aspects. The instructor then scheduled four activities to be completed in six sessions: a field trip to a mortuary service office, drafting a living will, film appreciation, and an introspective thinking activity in which students were asked to reflect on the most emotionally distressful events that they had experienced in their lifetimes. After each activity, the students performed structured journal-writing activities. Questions used in the Gibb' s reflective model were modified for use in guiding students in various activities designed to develop CT. The questions used for structured guidance included (1) describing events, (2) exploring feelings and responses to events, (3) applying CT skills (analysis assumption, evaluation and inductive reasoning) for self-analysis of responses, and (4) reflecting on how they could improve their responses or actions when they encountered similar situations in the future. After the instructor gave comments for unclear statements such as not apply the CT skills for

Published by Sciedu Press self-analysis in the journal, the students were required to make revisions in accordance with the comments and then resubmit the journal.

Finally, the class was divided into groups of five students for a two-session case study. Each group performed a different case study and answered a question set designed to induce application of the three CT skills during group discussion. Examples of questions included, 'What unspoken assumptions has Ms B made about her plans and actions?' and 'What would you do if you were Ms B? Why?' Each student was required to use the question set to interview all four other group members during or after the class and then use an online forum to give feedback on the responses.

\subsection{Participants}

Two groups of participants were recruited by purposive sampling from two classes of first-year students enrolled in a 2-year senior college gerontological care program at a southern Taiwan university. The inclusion criteria were completion of a 5-year junior college nursing program, at least 1 year of clinical nursing practicum experience, and no experience in structured journal writing or on-line discussion. The students enrolled in the LDS course were designated the LDS group. To avoid sample contamination and group equivalence, the not-LDS group comprised one class in the nursing curriculum in which none of the students were currently enrolled in the LDS course.

\subsection{Instruments and data collection}

The questionnaires included the Test of Critical Thinking Skills for Life-and-death Study (TCTS-LD) and the CTDS and written in Chinese. The 15 multiple-choice items on the TCTS-LD ${ }^{[32]}$ explore three domains of CT skills: analysis assumption, evaluation, and inductive reasoning. Six items, including suicide, immortality, attitudes toward dying patients, living will writing, myths and religion, comprised the inductive reasoning domain of the CTST-LD. For each item, a well-structured statement is followed by three response options, one of which has been identified by experts as the appropriate response for the given statement. For example, for the analysis assumption domain, a statement is followed by three assumptions, and the subject is required to select the assumption that is consistent with the statement. Each correct answer has a value of 1 point, and the maximum score is 15 . The concurrent validity of the test has been confirmed by a significant positive correlation $(r=.34, p<.001)$ with the Test of Critical Thinking Skills for Adults, ${ }^{[33]}$ and its construct validity has been demonstrated by confirmatory factor analysis in three-factor structure. The test has a KuderRichardson coefficient of .54, acceptable split-half reliability 
$(r=.47$ ICC $=.4)$, and test-retest reliability $(r=.58$; ICC $=.56)$. The total scale TCTS-LD had a Kuder-Richardson coefficient of .51 for this study, which indicated high. ${ }^{[34]}$

The 20-item CTDS designed by Yeh et al. ${ }^{[35]}$ which is based on two earlier tests ${ }^{[36,37]}$ and evaluate by expwers' content validity, is designed to measure personal intention to apply CT. The subject responds to each item on the CTDS using a five-point Likert scale ranging from 1 (never) to 5 (always). The maximum total score is 100 . The four components of the scale are reflective thinking ( 4 items), intellectual curiosity (3 items), open-mindedness (4 items), and systematic analysis (9 items), with factor correlation coefficient from .31 to .61 In Yeh et al. ${ }^{[35]}$ the Cronbach's alpha coefficients for the CTDS were $.88(\mathrm{n}=100)$ for the total scale and .58 to .83 for the subscales. In the current study, the total scale CTDS had a Cronbach's alpha coefficient of .90 .

In the pretest, the questionnaire was distributed to 76 volunteers. Of these 76 participants, the questionnaire was completed by 36 participants in the LDS group and by 34 participants in the not-LDS group. The two groups did not significantly $(p>.05)$ differ in age, grade point average, or education level of parents. The mean age was 21.44 in both groups.

Next, 14 volunteers were recruited for the consecutive qualitative part of this study. To ensure that their discussions generated sufficiently rich data, the inclusion criteria for this group were high class participation, adequate free time, and acquaintance with some members of the group.

\subsection{Ethical considerations}

After review and approval by the Research Development Committee (NO.96-02) at this institution, the researchers gave potential participants oral and written information about the study. Participants were ensured that participation was voluntary and that they could complete the questionnaires anonymously by using a number instead of a name. Participants were informed that their participation would not affect their academic records and that they were free to withdraw from the experiment at any time.

\subsection{Procedure}

For quantitative data collection, all questionnaires were distributed and gathered by a research assistant during class time without course instructors or researchers present. Then, two researchers used the SPSS V.17 statistical analysis program to analyze the survey data. Paired- $t$ test was used to explore the differences between pre-test and post-test. Oneway analysis of covariance (ANCOVA) was used to test the effects of the integrated teaching approach.
For qualitative data collection, two group interviews were performed by one researcher after the post-test. The interview questions were refined after conducting pilot interviews as following, "What have you experienced from the LDS course?" This question was followed by other questions like 'Which component of the LDS course impress you most?' and "How have the class activities or assignments influenced your thinking abilities?" Depending on the extent to which the participants engaged in discussion, the two group interviews last 45 minutes to 80 minutes. After the interviews were transcribed verbatim, content analysis was performed by extracting meaningful units, determining their underlying meanings, labeling the sub-themes as they emerged, and, finally, merging them into thematic units annotated with verbatim quotes as illustrative examples. ${ }^{[38]}$

\subsection{Rigour}

The trustworthiness of the qualitative part of study was reviewed by means of credibility, transferability, and confirmability. ${ }^{[39]}$ To ensure the credibility, the first author as interviewer with experience as a group leader, took notes during interview, listened to all interview recordings, and refined all verbatim, making sure that the transcripts were reliable. During the analysis, one colleague conferred and reached agreement on the categories to add further credibility. Transferability was facilitated by describing the selection and characteristics of participants, data collection in detail. Also the participants began to repeat themselves illustrating data saturation during group interview, the findings presented with quotations enhanced the transferability. Confirmability was assured by presenting the themes to have participants' checks.

\section{RESUltS}

\subsection{Quantitative description of learning}

\subsubsection{Within-group difference}

Paired $t$-tests were used to explore within-group differences in the scores of total thinking skills (TCTS-LD) and total disposition (CTDS).The scores for the total thinking skills and for the evaluation subscale were significantly higher on the post-test compared to the pre-test $(t=2.97, p=.005$; $t=$ $4.74, p<.001)$ in the LDS group. Whereas in the not-LDS group, only the score for the evaluation subscale was significantly higher on the post-test compared to the pre-test $(t=$ $6.50, p<.001$ ) (see Table 1). The mean scores for the preand post- tests of total thinking skills in each group were significantly increased (see Figure 1). 


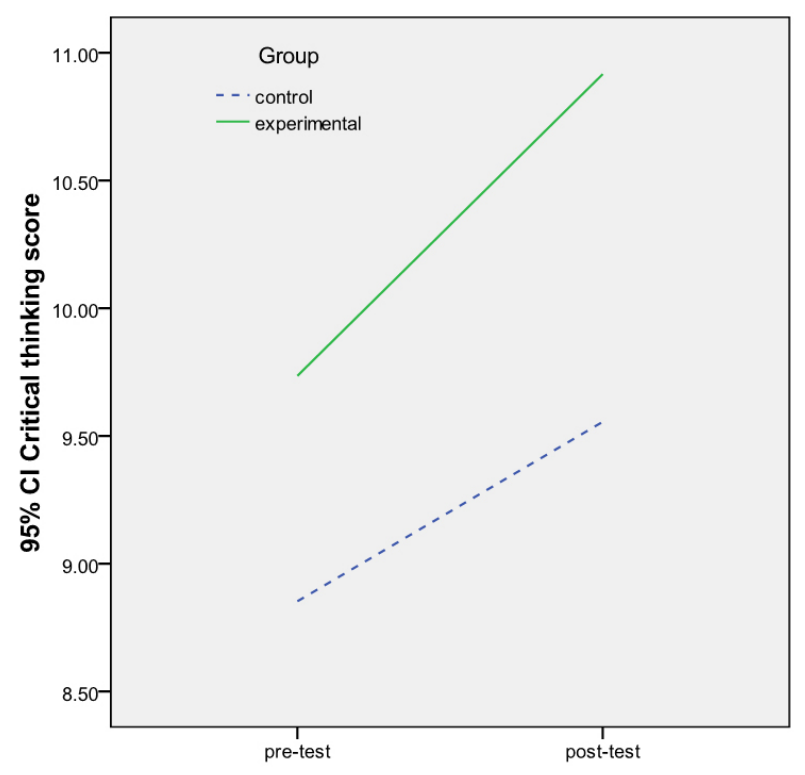

Figure 1. Comparison of critical thinking skills among groups and time

The mean scores for the pre- and post-tests of total disposition significantly differed between groups. In the LDS group, the score for reflective thinking was significantly higher on the post-test compared to the pre-test ( $t=2.26, p=.03$ ) The not-LDS group revealed no significant improvements in either the total disposition score or in the four subscale scores (see Table 1).

\subsubsection{Between-group difference}

Regarding total thinking skills, when using the pre-test score as a covariate to reduce error variance, the adjusted mean scores for total TCTS-LD scores differed between the two groups. However, the difference did not reach statistical significance $(F=3.58, p=.063)$. In further analysis of the three CT skills, only the adjusted mean scores for inductive thinking skill revealed a significant difference $(F=7.49$, $p=.008)$, which implies that the intervention affected the inductive subscale score. In analyses of the effect of learning on CT, Sample Power v. 2.0 obtained a power of .83 for inductive skills (see Table 2). Given an $\alpha$ value of .05 and an R-square for covariate of .033 (R-square of the post-test of Induction subscale regressed on the pre-test of Induction subscale), a large effect size (.33) was obtained for inductive skills (based on a between-group standard deviation of .39 computed from the means of 4.58 and 3.79 for each group divided by the within-group standard deviation of 1.12).

Table 1. Difference between pre- and post-tests on critical thinking skill and disposition in each group

\begin{tabular}{|c|c|c|c|c|c|}
\hline Item & Group & $\begin{array}{l}\text { Pretest } \\
(\mathrm{M} \pm \mathrm{SD})\end{array}$ & $\begin{array}{l}\text { Posttest } \\
(\mathrm{M} \pm \mathrm{SD})\end{array}$ & $\begin{array}{l}\text { Difference between pre-and-post test } \\
(\mathrm{M} \pm \mathrm{SD})\end{array}$ & $t(p)$ \\
\hline \multirow{2}{*}{ Total skills } & LDS & $9.55 \pm 2.34$ & $10.91 \pm 1.81$ & $1.36 \pm 2.74$ & $2.97^{* *}(.005)$ \\
\hline & Not-LDS & $8.85 \pm 1.94$ & $9.73 \pm 2.58$ & $0.88 \pm 2.55$ & $2.01(.052)$ \\
\hline \multirow{2}{*}{ Assumption } & LDS & $3.47 \pm 1.38$ & $3.83 \pm 1.18$ & $0.36 \pm 1.70$ & $1.26(.213)$ \\
\hline & Not-LDS & $3.32 \pm 1.27$ & $3.64 \pm 1.22$ & $0.32 \pm 1.24$ & $1.51(.140)$ \\
\hline \multirow{2}{*}{ Evaluation } & LDS & $1.55 \pm 0.90$ & $2.50 \pm 0.84$ & $0.94 \pm 1.19$ & $4.74^{* * *}(<.001)$ \\
\hline & Not-LDS & $1.32 \pm 0.58$ & $2.29 \pm 0.87$ & $0.97 \pm 0.86$ & $6.50^{* * *}(<.001)$ \\
\hline \multirow{2}{*}{ Induction } & LDS & $4.52 \pm 1.08$ & $4.58 \pm 0.87$ & $0.05 \pm 1.26$ & $0.26(.793)$ \\
\hline & Not-LDS & $4.20 \pm 1.17$ & $3.79 \pm 1.34$ & $0.41 \pm 1.67$ & $1.43(.160)$ \\
\hline \multirow{2}{*}{ Total disposition } & LDS & $72.61 \pm 10.31$ & $74.02 \pm 10.41$ & $1.41 \pm 9.94$ & 0.85 (.39) \\
\hline & Not-LDS & $75.20 \pm 9.84$ & $75.00 \pm 10.26$ & $0.20 \pm 10.90$ & $0.11(.91)$ \\
\hline \multirow{2}{*}{ Reflective thinking } & LDS & $10.05 \pm 2.35$ & $10.94 \pm 1.97$ & $0.88 \pm 2.35$ & $2.26^{*}(.03)$ \\
\hline & Not-LDS & $10.44 \pm 2.10$ & $11.02 \pm 1.94$ & $0.58 \pm 2.38$ & $1.43(.16)$ \\
\hline \multirow{2}{*}{ Curiosity } & LDS & $15.80 \pm 2.47$ & $15.58 \pm 2.24$ & $0.22 \pm 2.73$ & $0.48(.62)$ \\
\hline & Not-LDS & $16.17 \pm 1.78$ & $15.70 \pm 3.97$ & $0.47 \pm 2.24$ & $1.22(.23)$ \\
\hline \multirow{2}{*}{ Open-minded } & LDS & $14.61 \pm 2.51$ & $14.86 \pm 2.31$ & $0.25 \pm 2.62$ & $0.57(.57)$ \\
\hline & Not-LDS & $14.97 \pm 2.52$ & $14.67 \pm 2.44$ & $0.29 \pm 2.96$ & $0.57(.56)$ \\
\hline \multirow{2}{*}{ Systematic analysis } & LDS & $32.13 \pm 4.87$ & $32.63 \pm 5.23$ & $0.50 \pm 4.76$ & $0.62(.53)$ \\
\hline & Not-LDS & $33.61 \pm 4.40$ & $33.58 \pm 4.74$ & $0.02 \pm 4.79$ & $0.03(.97)$ \\
\hline
\end{tabular}

Note. ${ }^{*} p<.05,{ }^{* *} p<.01,{ }^{* * *} p<.001$

For total disposition, ANCOVA was used to analyze CTDS scores in terms of differences in adjusted mean post-test scores attributable to the educational intervention. The AN-
COVA results showed that the intervention did not significantly affect either subscale scores or total scores for total disposition (see Table 2). 
Table 2. Comparison of critical thinking skills and disposition between two groups at the post-test (taking pretest as a covariate $)(n=70)$

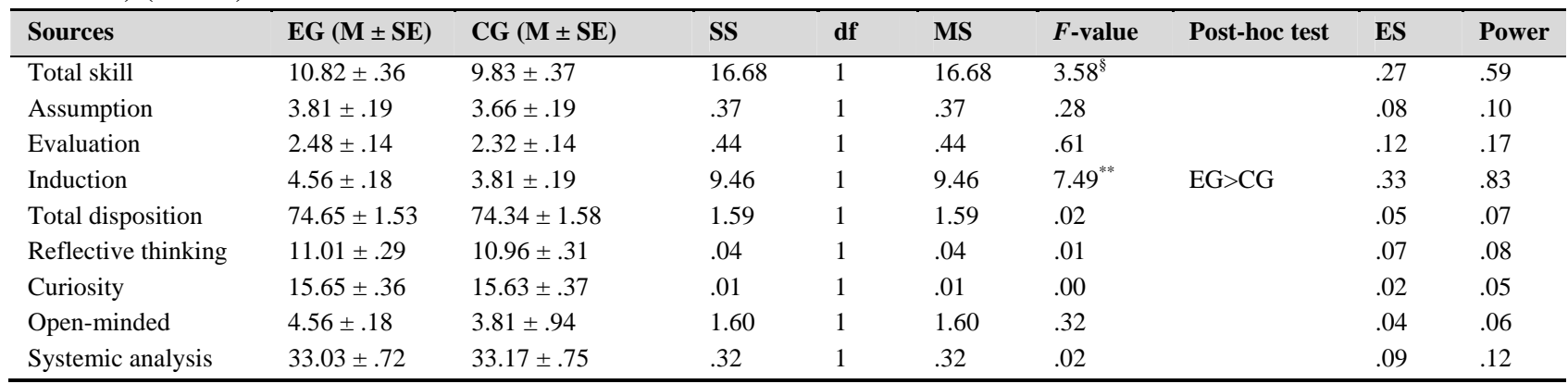

Note. ${ }^{\S} p<.1,{ }^{* *} p<.01$; EG: LDS Group; CG: Not-LDS Group; M: Adjusted Mean, SE: Standard Error, SS: Sum of Squares, MS: Mean Square, ES: Effect Size.

\subsection{Qualitative analysis of learning perceptions}

Two overarching themes that emerged in the group interviews, learning intentionality and unpreparedness, help explain how and why the life-death course integrated with reflecting activities maintained the inductive skill scores in the LDS group but did not significantly improve their scores for total skills or total disposition. The two themes comprised four subthemes: responding to stimuli, linking, unfamiliarity, and accessing issues. The themes and subthemes are presented below with quotations from the interviews. Representative examples of statements by the students regarding their perceptions of the intervention were selected from the pool of verbatim transcripts.

\subsubsection{Learning intentionality}

A common theme of the learning achieved by the intervention was learning intentionality which students presented self-directed and persistent manner on learning process by actively responding to course works or stimuli and linking their learning experiences with their future work or life. As their thinking and reflecting more on life and death issues, their learning intentionality increased. The participated students recognized their capability to learn from their life experiences and then take responsibility for learning more life and death events from others. Finally, facilitating students to apply inductive skills to make a comprehensive or probable conclusion based upon the evidence on issues about life and death.

Responding to stimuli. This subtheme indicated participants actively engaged in course activities. The participants indicated that the learning activities facilitated their participation in activities and their contemplation of death-related issues, which not only increased their intention to learn the course content and CT skills, but also broadened and deepened the CT skills needed to complete the course assignments. The students indicated that the course activities, including the guided journaling and the asynchronous online forum, provided opportunities to confirm their comprehension and to express their thoughts. The activities helped them to avoid self-centered thinking and to modify their viewpoints after observing and listening to others, both of which are very difficult for introverted students who lack confidence in making classroom presentations. Observations made by the participants included the following:

Now that I have completed this course, I have less fear of death and can easily discuss life and death issues with others (student S).

The online forum gave me a chance to reflect on my own thoughts and learn from the work of others (student C).

I was inspired by sharing opinions on the forum and by having face-to-face discussions of the topic with classmates...these activities taught me to interpret things from different perspectives, to think objectively, and to summarize my personal views on dying, life after death, living will, life meaning...(student $\mathrm{S}$ ).

Linking future. Learning intentionality was elicited by encouraging students to link their life experiences with their future work and life through reflective journal writing and discussions with others. Apparently, the learning that resulted from the reflective writing activity and from discussions with others was enhanced when students were induced to think about ways to improve their performance in the future. Course activities were scheduled before each journal writing assignment.

I try to live well every single day by contemplating my own death. I realized that I need to learn and do meaningful things for myself (student D).

I found that I should gather information and knowledge before making statements on the forum (student K).

The course activities inspired me to learn how to manage the death of a patient, which is important if I want to do my job effectively (student $\mathrm{S}$ ). 


\subsubsection{Unpreparedness}

The other common theme that emerged from the comments was unpreparedness which students were unprepared either in psychomotor skill or equipment for such integrated teaching strategies. The participants indicated that adequate preparation was essential for acquiring CT skills. Participants in this study indicated that they were unfamiliar with reflective journal writing and its benefits and that they did not know how to use the forum for discussion with their classmates. Some also said they had difficulty accessing a computer, which was required to complete the assignments. The two subthemes depicted further in the following.

Unfamiliarity. Although the students initially struggled to make journal entries after each class, they found that the journal writing activity became easier when they realized that reflecting on their experiences gave them important insights into ways to improve their skills in decision making and problem solving. Although journal writing is effective for promoting cognitive skills, the teacher must be able to model the skills effectively, and the students must be highly motivated and willing to make a sustained effort.

I didn't know how to write journals until the second assignment when the teacher provided a clear model. After completing six reflective journals in 3 months, I am still confused and tired....(student $\mathrm{H}$ )

At first, I found the journal writing activity perplexing, but, with practice, the activity helped me to recognize my assumptions (student $\mathrm{G}$ ).

Computer literacy and access issues. The online discussion forum required the students to be computer literate. For some participants, the 2 -week practice period, which comprised four 4-hour sessions, did not provide sufficient time to apply the CT skills needed to respond to the issues. Participating in the online discussion was also inconvenient for students who did not have access to a computer at home or in the dormitory. Additionally, poor computer literacy and poor writing and/or typing skills resulted in ambiguous statements that others could not understand. Examples of comments are as follows.

I feel that the 2-week practice period was too short to learn how to use the forum to practice critical thinking. Using typed messages for inquiries and responses was time-consuming, and the messages were difficult to understand (student A).

Thus, when responding to comments, instructors should be prepared to assess and motivate learners, to arrange learning resources and facilities, and to modify the intervention or its duration as needed to help anchor the CT skills of the students.

\section{Discussion}

The discussion integrated the findings of survey and interview to answer the research questions, and further explored the possible explanations for the findings. The survey showed comparable results in both groups on critical thinking disposition, but results reveal that participants in LDS do actively engage in reflection. Some students in the LDS group developed the personal dispositions needed for effective CT, such as broader and deeper reflection on death-related issues and intellectual courage to face death. For example, the course included a 2-hour field trip to a mortuary services office and journaling about the trip. The purpose was not only to encourage students to contemplate how they would respond to the death of a patient, but also to facilitate them to think about their own death and future encounters with death during their clinical career. The LDS course activities elicited reflection on how they would manage challenging life and work situations effectively in the future.

However, there were fourth possible explanations are proposed for the lack of improvement in thinking disposition. One possibility is the insufficient experience of the students in reflective journal writing and their insufficient understanding of the reflection concept. Although the instructor demonstrated the skills and corrected their journals, the students still needed more assistance in completing assignments related to reflection. It has been reported that the overuse of reflective models before students understanding of reflection can actually impede CT in nursing education. ${ }^{[40]}$ Second, an excessive workload or fatigue may have discouraged some students from completing the assigned tasks. Students who took this elective course did not expect it to require substantial time and effort. Therefore, they tended to consider the course activities (e.g., online discussion, analysis of CT skills through reflective journaling) an annoyance. Third, acquiring CT skills was difficult for students who had limited experience in life-and-death issues and who had difficulty accessing a computer to participate in online discussions. Finally, the CTDS was designed to measure attitudes regarding CT in general, not attitudes regarding CT about life-and-death issues. Further research is needed to develop instruments with sufficient sensitivity for specifically measuring changes in CT about life-and-death issues.

For the aspect of CT skills, although this study revealed comparable results in both groups on overall critical thinking skills, it is the first to show the LDS course might be possible for developing inductive skills in death-related issues. The findings partially agree with those of an earlier longitudinal study of changes in CT skills in three cohorts of students enrolled in a baccalaureate nursing program. ${ }^{[41]}$ In all three cohorts in that study, the largest change was in inductive 
skills. In the third cohort, the CT skills decreased, possibly due to insufficient motivation of the students to complete the third test. As observed in the control group in Beckies' study, ${ }^{[41]}$ the not-LDS group in the current study revealed decreased post-test scores in CT skills. A possible explanation is that, given the competing demands of their other courses, the post-test assessment had a low priority since the results would not have affected their grades.

In contrast, Hatcher ${ }^{[42]}$ reported the success of an integrated two-semester sequence for facilitating students in the repeated application of $\mathrm{CT}$ skills to reading and writing during a period exceeding 20 weeks. Again, for Eta square .1 with 70 participants, the effect size of .34 obtained in the current study is far smaller than the effect size of .87 reported in Hatcher ${ }^{[39]}$ Four possible explanations are proposed.

First, it is the different duration of time during which CT skills were repeatedly and consistently applied. Notably, the LDS course in this study was only one-semester long. Since these novel pedagogies are not intuitive for some students, instructors should prepare for the challenges of facilitating such teaching strategies. The interview results also showed that participants did not have sufficient time to become familiar with using the forum to practice CT skills by making inquiries and responses.

Second, effective CT skills are unlikely to be developed in a single course. A systematic review by Tiruneh et al. ${ }^{[43]}$ similarly reported that, without a systematic design, embedding CT instruction in an academic setting is ineffective for developing CT skills. Third, the CTST-LD is a newly developed test that assesses only three CT skills. In contrast, the California Critical Thinking Skills Test developed by Facione and Facione ${ }^{[44]}$ and applied in Hatcher ${ }^{[39]}$ assesses five skills. Hence, the CTST-LD may have limited use for revealing changes and for comparing outcomes. Fourth, the medium effect size of $.27^{[45]}$ and low power of .59 in the ANCOVA analysis for total scores for CT skills obtained in the current study suggest that the absence of a significant difference be-

\section{REFERENCES}

[1] Silva E. Measuring Skills for 21st-Century Learning. Phi Delta Kappan. 2009; 90(9): 630-4. http://dx.doi.org/10.1177/00317 2170909000905

[2] (NMC) NaMC. Standards for pre-registration education. 2010. [cited 2016 Feb.1]. Available from: http: //standards.nmc-uk.org/PreRegNursing/statutory/ background/Pages/more-standards-for-education.aspx

[3] Yu YM. Meaning and Development of Nursing Education Acred- tween groups may have resulted from an insufficient sample size.

Nevertheless, the LDS group in the current study revealed a significant increase in total CT skill scores at post-test. Similarly, an earlier one-group comparison of the effectiveness of teaching strategies (journal writing, service learning, case study and question discussion) used in a 14-week introductory leadership class of 80 students showed increases in total CT scores at the end of the course in comparison with pretest CT scores. ${ }^{[46]}$

\section{Conclusion}

This study showed that one semester session of LDS course integrating the conventional lecture format with reflective journaling over writing will, case study and field trip does not seem sufficient to significant increase total CT skills and intention, significantly maintained inductive thinking skill, reduced the fear of death and induced CT practices to construct knowledge about life and death. Notably, however, the improvement in total dispositions and skills apparently depended on the duration of the intervention and whether the students and instructors had previous training in CT. If possible, an emphasis should be placed on systematic design for curriculum in gerontology, resources and faculty development in teaching about critical thinking need to help create links that students may promote engaged thinking activities within their courses. These efforts will help to support the students' changes in personal disposition and more likely to broader and deeper reflection on death-related issues and intellectual courage to face death.

\section{ACKNOWLEDGEMENTS}

The authors like to thank the study participants for their contributions and the participating university's support in this study. The study has not received any funding. The authors declare no conflicts of interest.

\section{CONFlicts of InTEREST Disclosure}

The authors declare that there is no conflict of interest. itation in Taiwan: Taiwan Association of Nursing Education [updated Aug. 2010; cited 2016 Feb. 22]. Available from: http: //www.tane.org.tw/show.php?news_no $=38$

[4] Paul RW, Elder L. Critical Thinking Concepts and Tools. Tomales, CA: Foundation for Critical Thinking; 2009.

[5] Gelder TV. Teaching critical thinking: Some lessons from cognitive science. College Teaching. 2005; 53(1): 41-6. http://dx.doi.o $\mathrm{rg} / 10.3200 / \mathrm{CTCH} .53 .1 .41-48$

[6] Piergiovanni PR. Creating a Critical Thinker. College Teaching. 2014; 
62(3): 86-93. PMid:97066649. http://dx.doi.org/10.1080/8 7567555.2014 .896775

[7] Bartlett DJ, Cox PD. Measuring Change in Students' Critical Thinking Ability: Implications for Health Care Education. Journal of Allied Health. 2002; 31(2): 64. PMid:12040999.

[8] Lai ZB. Preliminary Study of Integrating "Critical Thinking" into the Teaching Methods of Educators of Early childhood. Taiwan Education Review. 2012; (675): 15-7.

[9] Yeh ML, Chen HH. Effects of an educational program with interactive videodisc systems in improving critical thinking dispositions for RN-BSN students in Taiwan. International Journal of Nursing Studies. 2005; 42(3): 333-40. PMid:15708020. http: //dx.doi.org/10.1016/j.ijnurstu.2004.06.008

[10] Hwang HL, Chen WT, Lin HS. Evaluation of life and death studies course on attitudes toward life and death among nursing students. The Kaohsiung Journal of Medical Sciences. 2005; 21(12): 552-60. http://dx.doi.org/10.1016/S1607-551X (09) 70207-4

[11] Yang YT, Chou HA. Beyond critical thinking skills: Investigating the relationship between critical thinking skills and dispositions through different online instructional strategies. British Journal of Educational Technology. 2008; 39(4): 666-84. http://dx.doi.org/10. $1111 / \mathrm{j} .1467-8535.2007 .00767 . \mathrm{x}$

[12] Malik AS, Malik RH. Twelve tips for effective lecturing in a PBL curriculum. Medical Teacher. 2012; 34(3): 198-204. http: //dx.doi.org/10.3109/0142159X.2011.588741

[13] Chi FM. Reflection as teaching inquiry: Examples from Taiwanese in-service teachers. Reflective Practice. 2010; 11(2): 171-83. http: //dx.doi.org/10.1080/14623941003672410

[14] Noblitt L, Vance DE, Smith MLD. A Comparison of Case Study and Traditional Teaching Methods for Improvement of Oral Communication and Critical-Thinking Skills. Journal of College Science Teaching. 2010; 39(5): 26-32. PMid:EJ887500.

[15] Rizopoulos LA, McCarthy P. Using Online Threaded Discussions: Best Practices for the Digital Learner. Journal of Educational Technology Systems. 2009; 37(4): 373-83. PMid:EJ852931.

[16] Kincheloe J. Teachers as Researchers: Qualitative Paths to Empowerment. New York: Falmer; 2003.

[17] Riddell T. Critical assumptions: thinking critically about critical thinking. Journal of Nursing Education. 2007; 46(3): 121-6. PMid:2009527695. Language: English. Entry Date: 20070907. Publication Type: journal article. Journal Subset: Core Nursing.

[18] Hayden HE, Moore-Russo D, Marino MR. One teacher's reflective journey and the evolution of a lesson: systematic reflection as a catalyst for adaptive expertise. Reflective Practice: International and Multidisciplinary Per-spectives. 2013; 14(1): 144-56. http://dx.doi.org/10.1080/14623943.2012.732950

[19] Wan Y, Lee DTF, Lee IFK, et al. Disposition towards critical thinking: a study of Chinese undergraduate nursing students. Journal of Advanced Nursing. 2000; 32(1): 84-90. http://dx.doi .org/10. $1046 / j \cdot 1365-2648.2000 .01417 . x$

[20] Perry CM, Power BM. Finding the truths in teacher preparation field experiences. Teacher Education Quarterly. 2004; 31(2): 125-36.

[21] Wang Q, Woo HL, Zhao J. Investigating critical thinking and knowledge construction in an interactive learning environment. Interactive Learning Environments. 2009; 17(1): 95-104. PMid:37140039. http://dx.doi.org/10.1080/10494820701706320

[22] Case J, Backes E, Babu S, et al. A pedagogical strategy to facilitate interdisciplinary reflective thinking and practice in rehabilitation counseling students. Rehabilitation Research, Policy \& Education. 2012; 26(2/3): 271-82.

Published by Sciedu Press
[23] Nielsen A, Stragnell S, Jester P. Educational innovations: Guide for reflection using the clinical judgment model. Journal of Nursing Education. 2007; 46(11): 513-6. PMid:18019109.

[24] Hauenstein AD. A Conceptual Framework for Educational Objectives: a holistic approach to traditional taxonomies. Lanham, Md: University Press of America; 1998.

[25] Richard P, Elder L. Critical Thinking: Strategies for Improving Student Learning, Part II. Journal of Developmental Education. 2008; 32(2): 34-5.

[26] Tüfekci FG, Küçükoğlu S, Bölükbaş N, et al. Critical thinking dispositions of nursing students and influencing factors in Turkey. Health Medicine. 2011; 5(4): 831-6.

[27] Mann K, Gordon J, MacLeod A. Reflection and reflective practice in health professions education: a systematic review. Adv Health Sci Educ Theory Pract. 2009; 14(4): 595-621. PMid:18034364. http://dx.doi.org/10.1007/s10459-007-9090-2

[28] Gibb G. Learning by Doing: A guide to teaching and learning methods. Further Education Unit. Oxford: Oxford Brookes University; 1988.

[29] Johns C. Becoming a reflective practitioner. 4 ed. Oxford: WileyBlackwell Publishing; 2013.

[30] Jonassen D. Objectivism versus constructivism: Do we need a new philosophical paradigm? Educational Technology Research and Development. 1991; 39(3): 5-14. http://dx.doi.org/10.1007/B F02296434

[31] Hayes B, Bonner A, Douglas C. An introduction to mixed methods research for nephrology nurses. Renal Society of Australasia Journal. 2013; 9(1): 8-14.

[32] Hwang HL, Lin HS, Wang HH. The revised critical thinking skills scale for a life-and-death course: preliminary scale refinement. The Journal of Nursing Research. 2010; 18(4): 299-310. PMid:21139450. http://dx.doi.org/10.1097/JNR. 0b013e3181fc6536

[33] Yeh Y, Chen Y, Shea J, et al. Devalopment of critical thinking skill test for adult. Psychological Testing. 2001; 48(2): 35-50.

[34] Cohen J. Statistical power analysis for the behavioral sciences. 2nd ed. Hillsdale, NJ: Lawrence Erlbaum; 1988.

[35] Yeh YC, Yeh PL, Hsieh CC. The Development of The Test of Criticalthinking Skills for Primary and Secondary School Students. Psychology Test. 2000; 47(1): 27-46.

[36] Ennis RH. A Logical Basis for Measuring Critical Thinking Skills. Educational Leadership. 1985; 43(2): 44-8.

[37] Watson G, Glaser EM. Watson-Glaser critical thinking appraisal manual. San Antonio: The Psychologic Corporation: Harcourt Brace Jovanovich, Inc.; 1994.

[38] Graneheim UH, Lundman B. Qualitative content analysis in nursing research: concepts, procedures and measures to achieve trustworthiness. Nurse Education Today. 2004; 24(2): 105-12. PMid:14769454. http://dx.doi.org/10.1016/j.nedt.2003.10.001

[39] AG T. Part II. Rigour in qualitative research: complexities and solutions. Nurse Res. 2005; 13(1): 29-42. PMid:16220839.

[40] Coward M. Does the use of reflective models restrict critical thinking and therefore learning in nurse education? What have we done? Nurse Education Today. 2011; 31(8): 883-6. PMid:2011352541. ht tp://dx.doi.org/10.1016/j.nedt.2011.01.012. Language: English. Entry Date: In Process. Revision Date: 20111118. Publication Type: journal article. Journal Subset: Europe.

[41] Beckie TM, Lowry LW, Barnett S. Assessing critical thinking in baccalaureate nursing students: a longitudinal study. Holistic Nursing Practice. 2001; 15(3): 18-26. http://dx.doi .org/10.1097/000 04650-200104000-00006 
[42] Hatcher DL. Stand-alone versus integrated critical thinking courses. The Journal of General Education. 2006; 55(3): 247-72. http: //dx.doi.org/10.1353/jge.2007.0002

[43] Tiruneh DT, Verburgh A, Elen J. Effectiveness of critical thinking instruction in higher education: A systematic review of intervention studies. Higher Education Studies. 2014; 4(1): 1-17. http://dx.doi.org/10.5539/hes.v4n1p1
[44] Facione P, Facione N. The California Critical Thinking Skills Test: Form A and B Test Manual. Milbrae, CA: California Academic Press; 1994.

[45] Cohen J. Statistical Power Analysis for the Behavioral Sciences. New York: Academic Press; 1977.

[46] Burbach ME, Matkin GS, Frits SM. Teaching critical thinking in an instroductory leadership course utilizing active learning strategies: A confirmatiory study. College Student Journal. 2004; 38(3): 482-93. 